1 Hattersley AT, Tooke JE. The fetal insulin hypothesis: an alternative explanation of the association of low birth weight with diabetes and vascular disease. Lancet 1999;353:1789-92.

2 Lindsay RS, Dabelea D, Roumain J, Hanson RL, Bennett PH, Knowler WC. Type 2 diabetes and low birth weight: the role of paternal inheritance in the association of low birth weight and diabetes. Diabetes $2000 \cdot 49 \cdot 445-9$.

3 Rasmussen F, Davey Smith G, Sterne J, Tynelius P, Leon DA. Birth char- acteristics of offspring and parental diabetes. Am J Epidemiol 2001;153(suppl):S47.

4 Pennison EH, Egerman RS. Perinatal outcomes in gestational diabetes: a comparison of criteria for diagnosis. Am J Obstet Gynecol 2001;184:1118-21. 5 Butler NR, Bonham DG. Perinatal mortality. Edinburgh: Livingstone, 1963.

(Accepted 22 July 2002)

\title{
Incidence of coronary heart disease in a health authority in London: review of a community register
}

\author{
Steven J Sutcliffe, Kevin F Fox, David A Wood, Angela Sutcliffe, Kathryn Stock, Melissa Wright, \\ Fawaz Akhras, Ed Langford
}

Cardiovascular Research Group, National Heart and Lung Institute, Faculty of Medicine, Science, Technology and Medicine, Charing Cross Hospital, London W6 8RF

Steven J Sutcliffe research fellow Kevin F Fox research fellow David A Wood professor of cardiovascular medicine

Angela Sutcliffe research nurse Kathryn Stock research nurse Melissa Wright statistician

Bromley Hospital, Bromley Hospitals NHS Trust, London BR2 9AQ

Fawaz Akhras consultant cardiologist Ed Langford consultant cardiologist

Correspondence to: D Wood

d.wood@ic.ac.uk

BMJ 2003;326:20 Imperial College of

Strategies to reduce deaths from coronary heart disease need to take into account clinical presentation of the disease. ${ }^{1-4}$ We used a coronary heart register to examine non-fatal and fatal presentations of the disease in a health authority in outer London.

\section{Methods and results}

Bromley Health Authority employs 151 general practitioners with a total of 295584 patients on their lists. The Bromley coronary register prospectively identified all incidences of coronary heart disease in people aged 16-74 from September 1996 to August 1997 for men and from September 1996 to May 1998 for women.

The health authority invited general practitioners to refer new cases of suspected exertional angina to a daily "rapid access" clinic for patients with chest pain at Bromley Hospital. All patients using the clinic and cardiology outpatients were screened. Inpatients admitted to the hospital through its emergency department were screened and followed up on the ward until diagnosis. The two coroner's offices for the authority identified sudden deaths in the community and inpatient deaths that had been reported to them. The authority provided data on all Bromley residents admitted to hospitals in England and Wales with ICD-9 (international classification of diseases, ninth revision) codes for coronary artery disease (410-414).We retrospectively audited a random $8 / 59$ general practices for new prescriptions of nitrates (for angina); we found four missed cases during the registration period. Ethical approval was provided by Bromley local research ethics committee.

A panel of three consultant cardiologists reviewed the patients' presenting history, clinical examination, electrocardiogram, results of blood tests, results of tests measuring stress during exercise, myocardial perfusion scans, and necropsy information where available; they did not review coronary angiograms. The cardiologists classified cases as sudden cardiac death (death attributed

Incidence of coronary heart disease per 100000 population per year in people aged 25-74 in Bromley Health Authority

\begin{tabular}{lccccc} 
& \multicolumn{2}{c}{ Men } & & \multicolumn{2}{c}{ Women } \\
\cline { 2 - 3 } \cline { 6 - 7 } Presentation & Incidence $(\mathbf{9 5 \%} \mathbf{~ C I})$ & $\%$ & & Incidence $(\mathbf{9 5 \%} \mathbf{C l})$ & \% \\
\hline Exertional angina & $172(146$ to 201$)$ & 41 & & $77(63$ to 91$)$ & 52 \\
\hline Acute myocardial infarction & $133(110$ to 159$)$ & 32 & & $32(24$ to 42$)$ & 22 \\
\hline Sudden cardiac death & $57(43$ to 75$)$ & 14 & & $19(13$ to 27$)$ & 13 \\
\hline Unstable angina & $52(39$ to 70$)$ & 13 & & $19(13$ to 27$)$ & 13
\end{tabular}

to coronary artery disease), acute myocardial infarction (typical history and resting electrocardiogram changes and creatine kinase concentrations twice the normal upper limit), unstable angina (typical chest pain at rest or rapidly worsening exertional pain without raised creatine kinase concentrations), or exertional angina (typical history and information from exercise testing or perfusion scanning, which was available in $92 \%$ of cases) (table 1). To test whether decisions were reproducible, 100 randomly selected cases (about $10 \%$ of the total) were reclassified; agreement was good (Cohen's $\kappa=0.86$ ).

We found 378 cases of men and 242 cases of women who first presented with coronary heart disease, all in the age group 25-74; we found no cases aged 16-24. The incidence of the disease was $414 / 100000$ population per year in men and $147 / 100000$ population per year in women. Incidences were greater in older people in both sexes, and at all ages they were significantly higher in men.

\section{Comment}

Most coronary heart disease presents in treatable form. Considerable potential exists to reduce the risk of recurrent disease and specifically to prevent patients with angina and well preserved ventricular function from progressing to myocardial infarction and death. ${ }^{5}$ We found that $86 \%$ of men and $87 \%$ of women present alive to medical services with their first presentation of coronary heart disease; $54 \%$ of men and $65 \%$ of women have preserved myocardium.

We thank the coroners for their help.

Contributors: SJS ran the clinic for people with chest pain; KFF primarily wrote the paper; DAW designed and supervised the study, reviewed cases, and contributed to the manuscript; KS and AS ran the register; MW did the statistical analysis; and FA and EL reviewed the cases. All authors reviewed and revised the manuscript. DAW is guarantor.

Funding: Preventive Cardiology Trust.

Competing interests: None declared.

1 Department of Health. Saving lives: our healthier nation. London: Stationery Office, 1999.

2 Department of Health. The national service framework for coronary heart disease. London: Stationery Office, 2000.

3 Gandhi MM, Lampe F, Wood DA. Incidence, clinical characteristics and short-term prognosis of angina pectoris. Heart 1995;73:193-8.

4 Kannel WB, Feinleib M. Natural history of angina pectoris in the Framingham study. Am Heart J 1972;29:154-63.

5 Wood DA, Durrington P, Poulter N, McInnes G, Rees A, Wray R on behalf of the British Cardiac Society, British Hyperlipidaemia Association, British Hypertension Society, and British Diabetic Association. Joint British recommendations on prevention of coronary heart disease in clinical practice. Heart 1998;80(suppl 2):1-26S.

(Accepted 27 July 2002) 